\title{
ALIMENTAÇÃO DA CRIANĢA DE 0 A 1 ANO
}

\author{
Abigail Ribeiro, Elisabeth Borges \\ Pereira, Leonilda Rosa, Maria Inês \\ Burini, Solange Santo Pietro, Regi- \\ na Loti Serrano. *
}

\section{- ALIMENTOS:}

Alimento é tudo o que o organismo recebe do ambiente para sua constituição, atividade e conservação; isto basta para mostrar a sua importância.

Todos os alimentos que usamos são formados por algumas espécies de componentes: água, proteinas gorduras, hidratos de carbono, sais minerais e vitaminas.

Não há um componente mais importante que o outro. Todos são necessários embora em quantidades diferentes; a falta ou a insuficiência embora em quantidades diferentes; só a falta ou a insuficiência dêles causa prejuízos diversos. O que é importante é a proporção em que cada um entra na alimentação, especialmente da criança.

Água: não é um alimento no sentido vulgar da palavra; todavia é um dos elementos indispensáveis ao organismo vivo. Representa 60 a $70 \%$ do peso total do corpo humano, sendo o meio de transporte e dissolução dos alimentos ingeridos pelo homem até chegar às células, bem como meio de transporte e eliminação dos detritos procedentes da desassimilação. A perda de $20 \%$ do total de líquido do organismo poderá acarretar a morte pela intensa desiđratação.

Proteínas: são os componentes principais dos alimentos de origem animal: leite, ovos e carne, sendo encontrados também em alguns alimentos vegetais: soja, milho, trigo, arroz etc. A função principal das proteínas é fornecer aminoácidos imprescindiveis à vida, pois dêstes depende bàsicamente a estrutura de cada célula do organismo humano.

* Alunas do Curso de Graduação em Saúde Pública da Escola de Enfermagem da USP. 1971 
Gorduras: são substâncias graxas de alto teor energético. Entre elas temos as gorduras, os azeites e substâncias lipoides encontradas

na nata do leite e na gordura dos animais. A função principal das gorduras é o fornecimento de energia calorica.

Hidratos de Carbono: são as farinhas obtidas de cereais (arroz, milho, aveia, centeio, cevada), de raizes (mandioca) e de tuberculos (como a batata e o cará); e os açucares, tanto de cana e de beterraba como os contidos nas frutas e no mel. A função principal dos hidratos de carbono é formar os elementos de oxigenação dos tecidos e manter as reservas do organismo.

Sais Minerais: os elementos minerais constituem pequena proporção dos tecidos corporais, mas são essenciais como componentes formativos em muitos dos fenomenos vitais. Alguns dêles formam tecidos duros como os ossos e os dentes; outros se encontram nos líquidos e nos tecidos moles. O equilíbrio dos ions minerais é importante em algumas funções como por exemplo a quantidade e proporção de cálcio e fósforo na osteogênese; a ação do cálcio e potásio no líquido extracelular na atividade muscular normal. O sódio e potássio são substâncias de grande importância no contrôle osmótico do metabolismo hidrico. Outros minerais podem atuar como catalizadores nos sistemas enzimáticos, ou como partes de compostos orgânicos corporais, como o ferro na hemoglobina, o iodo na tiroxina e o cobalto da vitamina B12. Dos minerais necessários ao organismo temos: cálcio, fósforo, potássio, cloro, sódio, magnésio, ferro e iodo, sendo encontrados em várias formas nos alimentos naturais ou combinados com proteínas, acidos graxos e hidratos de carbono.

Vitaminas: são potentes compostos organicos presentes em pequenas concentrações nos alimentos: tem funções especificas e vitais nas células e tecidos da economia, agindo como catalizadores biológicos nos muitos sistemas enzimáticos corporais. São, protetoras e reguladoras do equilibrio vital, influindo também no sistema de proteção às infecções. São encontradas nos cereais, frutas, verduras e azeites.

Outros componentes dos alimentos que não são propriamente alimentos mas influem na boa alimentação são as substâncias que dão côr, gosto ou sabor aos mesmos e a celulose. A variação de côr após os primeiros meses de vida tanto nas refeições de sal (pela Introdução dos legumes e verduras) pode ser estimulante psiquico do apetite. A celulose é o bagaço dos legumes, das verduras e das frutas que estimulam o movimento do tubo digestivo, prevenindo ou corrigindo a prisão de ventre; às vêzes estimulam em excesso provocando diarréia decorrente do desequilíbrio da dieta.

Vejamos os requisitos e condições que são comuns à alimentação de todas as crianças. 
Quantidade Adequada: a criança se alimenta impulsionada por dois estimulos:

a) a necessidade do organismo para que cresça e se desenvolva.

b) a sensação de apetite ou de fome despertada pela necessidade do organismo. Na criança normal, a sensação de apetite ou de fome solicita a quantidade de alimento necessária. Dêste modo a quantidade certa de alimentação equilibrada para uma criança é a que satisfaz promovendo o seu bom desenvolvimento, que é avaliado pelo aumento moderado do peso, desenvolvimento de músculos firmes, eliminação satisfatória, sono tranquilo etc.

\section{Horário e Número de Refeições:}

O horário não deve ser rigido. A rigidez obrigaria deixar a criança com fome, se a sentisse antes da hora fixada. A quase totalidade das crianças se dá bem com um horário de intervalos variáveis entre 3:00 e 4:00 hrs. Durante a noite deve-se oferecer chá ou água, pois o choro pode ser decorrente da sêde.

O número de refeições varia conforme os intervalos e vice versa. Com espaços de 3 a 4:00 hrs. as refeições são em número de 5 ou 6 por dia. Há crianças que se satisfazem com 4 refeições diárias mesmo a partir do segundo semestre de vida.

A necessidade de alimento pode ser expressa pelo choro mas é sempre útil verificar previamente se não há outra causa inclusive sêde.

\section{Correlação Adequada:}

Correlação adequada é a boa proporção em que entram os componentes alimentares mencionados anteriormente no cardápio da criança.

\section{Aleitamento Materno:}

Deve ser mantido sempre que possível, pois o aleitamento ao seio materno tem dupla vantagem: atende a profunda necessidade sentimental da criança pequena e é menor a possibilidade de contaminação e poluição.

\section{Apresentação Adequada:}

A apresentação deve estar de acôrdo com a capacidade de digestão da criança nas idades que vai alcançando.

\section{Dosagem Correta:}

Cada novo alimento deve ser usado inicialmente em pequenas quantidades, devendo ser aumentado aos poucos de acôrdo com a 
aceitação. Isto serve para tatear a tolerância digestiva e do paladar do bebê, e verificar a possibilidade de manifestações alérgicas.

\section{Dieta Variada:}

A dieta deve ser tạ̃o variada quanto possivel, visando com isso aumentar a possibilidade do recebimento de multiplicidade de substâncias nutritivas (principalmente proteinas, sais minerais e vitaminas) e evitar a monotonia do cardápio a que pode ser causa de falta de apetite.

\section{Dieta Equilibrada:}

Ter o cuidado de equilibrar os efeitos laxante e obstipante dos componentes da alimentação. Há alimentos que tendem a provocar evacuações mais frequentes e moles ou líquidas, e há alimentos que tendem a provocar evacuações mais espaçadas e secas.

\section{Condições favoraveis:}

Alimentação deve ser dada de modo a favorecer boa aceitação e a não prejudicar o apetite, procurando satisfazer as seguintes condições:

- ambiente agradável

- boa situação corporal da criança

- não ter pressa

- temperatura razoável dos alimentos

- respeito às recusas de alimentos, porque entre as crianças existem algumas que percebem quando já estão satisfeitas e existem outras que não percebem e terminam por vomitar o excesso.

\section{ASPECTOS GERAIS:}

A higiene alimentar é de máxima importância no primeiro mês de vida da criança. Como o seu aparelho digestivo não está ainda ajustado ao trabalho da digestão, os erros na sua alimentação podem ser muito mais prejudiciais que em qualquer outra idade.

Nêste periodo a criança recebe: água, leite, vitaminas em gôtas e caldo de frutas.

Água: água ou chá devem ser oferecidos até que a criança recuse por si mesma. A criança deixa de aceitar água no momento exato em que desaparece a sensação de sede.

Leite de Peito: nos primeiros 3 a 4 dias de vida recebe o colostro; em seguida vem o leite. A produção do leite pela mãe é extremamente variável; pode ser suficiente, sobrar ou então necessitar ajuda de mamadeira com leite de vaca. Algumas mães não conseguem amamentar 
o filho nem nos primeiros 30 dias e outras conseguem até 9 a 10 meses de idade. - A grande maioria das mães amamenta até o $3 .^{\circ}$ ou $4 .^{\circ}$ mês.

Leite de Vaca: o leite de vaca deverá ser introduzido no cardápio do rescém nascido sempre que a mãe não tiver leite ou quando o tiver em quantidade insuficiente (é o aleitamento artificial ou aleitamento misto). Isto quer dizer que a mãe deve ser alertada em alguns sinais de fome a fim de providenciar a complementação com leite de vaca na alimentação do filho.

Estar alerta para as situações que indicam fome:

-.. o recém nascido exige o seio materno a intervalos curtos

- recém nascido tem muita sede e toma muita água

- o recém nascido apresenta prisão de ventre com fezes endurecidas.

Vitamina A e D: qualquer que seja o regime alimentar da criança ela deverá receber vitamina $\mathrm{A}$ e $\mathrm{D}$ em gôtas desde 20 dias até 2 anos. As vitaminas devem ser dadas em açucar ou com um pouco de água, e nunca no leite, pois se o recém nascido deixar resto do mesmo não receberá as dosagens necessárias de vitaminas.

Caldo de Frutas: A criança deve receber caldo fresco de frutas no final do periodo neo-natal (com 30 dias). A melhor fruta é a laranja, qu epoderá ser substituida por cenoura ou tomate. Deverão ser dadas, puras ou eventualmente com açucar (sem água). Daí a não indicação do limão, que seria água com algumas gôtas de limão. Se a criança apresentar intolerância pelo suco durante muito tempo, convirá então ministrar vitamina A, D e C, 10 gôtas por dia.

Refeição de Sal: com 4 a 4 e meio meses de vida deve ser introduzida no cardápio da criança a primeira refeição de sal, que consiste na sopa de legumes e verduras preparada em caldo de carne com algum tempero e engrossada com cereais.

Quando a criança começar a receber esta refeição deve-se diminuir aos poucos a quantidade de farinha que está sendo acrescentada ao leite até que chegue a receber sòmente leite com açúcar.

Observação: Nunca usar o liquidificador (vicia a criança nesta apresentação cremosa), de preferência usar peneira e posteriormente, apenas amassar com o garfo. O importante é que o pirão seja saboroso e que se tome cuidado com o tipo de mistura dos alimentos.

Sobremesa de Frutas Frescas e Esmagadas: Depois de 8 a 10 dias do uso da refeição de sal, a criança começará receber sobremesa de frutas frescas e esmagadas, simples ou adoçadas com açúcar: banana, mamão, abacate ou maçã raspada. Deve-se começar com pequena quantidade e ir aumentando aos poucos. 
Gema de Ovo Cozido: a gema de ovo é um alimento de alto valor e seu uso deve começar logo que a criança se tenha habituado à refeição de sal com a sobremesa de frutas. Deve-se começar em dias alternados, com $1 / 4$ de gema e aumentando para $1 / 2,3 / 4$ até 1 gema inteira. Se a criança tolerar bem, pode se dar uma gema diàriamente, bem esmagada junto com duas ou três colherinhas de água, formando papinha sem grumos e misturando a uma das refeições diárias. O uso da gema crua pode ser introduzido depois de 2 ou 3 meses.

\section{PROBLEMAS DE ALIMENTAÇÃO DO LACTENTE:}

Fatores a serem observados na orientação dietética.

Fator Constitucional: é da constituição da criança que depende a escolha da natureza, volume e intervalo das refeições, o que representa importante elemento na orientação dietética.

A necessidade alimentar é variável assim como, a tolerância da mucosa gastro intestinal, a natureza e concentração do leite. E um fator individual.

\section{Condições que o Alimento deve satisfazer:}

A indicação de um alimento deve observar as seguintes condições:

- ritmo de crescimento

- tolerância gastro-intestinal

- necessidades nutritivas

- higiene do alimento

- situação econômica

E diante disso levar em conta que:

a) o leite materno é o mais indicado para o crescimento do lactante

b) a tolerância gastro intestinal é baixa para alimentos com alto teor de gorduras ou hidratos de carbono. Não se indicará leite integral ou condensado para o recém nascido. Daí compreender-se a tendência atual da troca das farinhas pelas dextrinas e maltoses. Os hidratos de carbono fermentesciveis, como a sacarose são mal tolerados. As proteínas em taxas moderadas são toleradas.

c) qualquer que seja o leite utilizado deverá satisfazer integralmente as necessidades nutritivas do lactente, quanto às proteínas, hidratos de carbono, sais minerais e vitaminas. Para isso deve haver adequada composição do alimento e volume suficiente.

d) contaminação do leite é causa fundamental da incidência de dispepsias, devido a manipulação. O leite sugado diretamente no seio permite esterilidade que nenhuma forma de alimentação artificial pode conceder, porque é isento do contato com o ambiente. As condições higiênicas do preparador são fundamentais para fornecimento do leite relativamente estéril. 
e) nos meios de baixa condição sócio-econômica, o leite materno constitui único alimento de que dispõe o lactente; daí o aleitamento prolongar-se além da época necessária. A aquisição dos leites industrializados é impossível nas classes pobres.

\section{- PROFILAXIA DE CARENCIAS POSSIVEIS:}

A alimentação lactea exclusiva por tempo prolongado, leva às carências: protéica, mineral e vitaminica. A carência de ferro manifesta-se após o $6 .^{\circ}$ mês e é caracterizada pela anemia hipocromica. Daí a necessidade de administrar sais ferrosos a partir da primeira semana, junto com complementos alimentares como suco de frutas, papa de legumes, ovo e carne. Administrar vitamica C e Complexo B a partir da 2a. semana.

\section{- PSICOLOGIA DA ALIMENTAÇÃO:}

Convém observar as necessidades alimentares da criança e ajustar o horário para satisfazê-las. Certos fatores como: temperatura inconveniente do leite, luminosidade, posição inadequada da criança e nervosismo materno durante a amamentação, tornam a alimentação penosa.

Bakwi considera a anorexia do lactente, como devida a duas causas: neurose constitucional e negativismo desenvolvido nos últimos 3 meses do primeiro ano de vida.

\section{- ALIMENTAÇÃO NATURAL:}

A amamentação ao seio materno é uma imposição biológica pois satisfaz as necessidades psiquicas e fisiológicas do lactente. Levandose em conta o que foi dito anteriormente sôbre a importância da higiene do leite, deve-se limpar o mamilo com água fervida, antes de cada mamada.

A apresentação do colostro em quantidades progressivamente maiores recebe a denominação de Apojadura e se verifica no $2 .^{\circ}$ ou $30^{\circ}$ dia nas multiparas e no $3 .^{\circ}$ e $4 .^{\circ}$ dias nas primiparas. E acompanhado de aumento da turgescência da mama e aumento da temperatura podendo até causar dor.

O volume do leite secretado nas 24 horas varia grandemente de acordo com a constituição física da mãe, nutrição, raça, paridade, estimulos psiquicos, frequência da sucção, período do dia ou da noite e horário da mamada. O volume normal varia de 800 a $1200 \mathrm{ml}$ diários.

o Colostro é o primeiro e mais adequado alimento para o lactente nos primeiros dias de vida. Possui leve ação laxativa, destinada a favorecer a eliminação do mecônio e tem alto valor imunitário! E um 
liquido espesso, viscoso e amarelo e a sua completa passagem para o leite definitivo leva 20 dias.

o Leite definitivo é o melhor tolerado pela criança. Imuniza-a contra certas infecções pelos anticorpos que inclui e tem menor possibilidade de causar reações alérgicas. Sua digestão exige o minimo de energia do organismo, sendo rápida, completa e utilizando $96 \%$ dos constituintes do leite no seu aproveitamento.

\section{Caracteres Físico-Químicos do Leite Humano:}

1 - Baixo teor de proteinas e minerais, o que constitui seu ponto vulnerável.

2 - Composição protéica particular - é considerado um leite albuminoso. Suas proteínas compreendem partes iguais de caseina e lactoalbumina.

3 - Melhor qualidade das gorduras - formam uma emulsão mais fina.

4 - Maior teor de lactose

5 - Enzimas - ação enzimática total, condicionando aproveitamento completo dos constituintes do leite.

\section{OBSTACULOS A AMAMENTAÇÃO:}

O aleitamento é, por si mesmo, um ato que exige delicadeza de atitudes, e um intenso estado de paz espiritual nem sempre obtido com facilidade, em se tratando de mães nervosas. A técnica defeituosa de colocar a criança no seio, bem como a excitabilidade da mãe ou da criança tornam a mamada ineficiente. Modificações do leite por substâncias ingeridas pela mãe podem provocar a recusa do seio.

\section{PRATICA DA AMAMENTAÇÃO}

A maioria das anorexias e das neuroses da infância, tem origem nêste período e estão diretamente relacionadas com a prática de administração do alimento.

\section{Horários das Mamadas:}

Dependem das condições de vitalidade - apetite, fôrça de sucção e progresso no peso.

Poderá ser de 5 a 6 mamadas no periodo de 24 horas, com um repouso noturno de 6 a 8 horas (6-9-12-15-18-22)

\section{Duração das Mamadas:}

Dependem das condições de eficiência da sucção e da produção do leite - em média 5 a 10 minutos em cada seio. 


\section{Posição:}

A mãe sentada confortávelmente em cadeira baixa, lactente em decubito semi-elevado (em contato com o corpo materno). A proximidade dá segurança e tranquilidade à criança.

Após a mamada há necessidade de se esperar a eructação, que é a expulsão do ar deglutido com o leite que se encontra no estomago. Este ar, sob a forma de grandes bôlhas, provoca distensão gástrica e abdominal, podendo chegar aos vômitos, recusa do alimento, sensação dolorosa, inquietação e dispnéia. Não deitar o bebê enquanto não se verificar a eructação 2 a 4 vezes em média.

\section{RESUMO}

Os autores fazem uma análise suscinta dos componentes alimentares e de suas funções principais no organismo humano. Mostram a seguir a importância da alimentação adequada no crescimento da criança, apontando os requisitos básicos e condições a serem considerados na boa alimentação: quantidade, horário e número de refeições, apresentação, dosagem, dieta equilibrada e condições ambientais. Enfatizam o valor do aleitamento materno. A higiene alimentar é tratada visando principalmene a criança no $1 .^{\circ}$ mês de vida, quando os erros alimentares podem prejudicar muito o processo de crescjmento. Os problemas da alimentação do lactente são tratados especificamente incluindo sugestões e recomendações sobre a prática da amamentação.

\section{SUMMARY}

\section{Feeding of infants from birth to one year age}

They enphasize the value of breast feeding and food hygiene, of food and their main functions in the human body. They indicate the importance of appropriate feeding for child growth, pointing out the basic requirement and conditions to be considered: quantity, schedule of meals, appearance of food, dosage, balanced diet and ambiental conditions.

They enfhasize the value of breast feeding and food hygiene, particularly during the child's first month of life, when alimentary mistakes can interfere more readily with the growing process. Food problems of the suckling are considered. Suggestions and recommendations in relations to breast feeding practice are included. 


\section{BIBLIOGRAFIA}

MITChelL, H.S. et al - Nutricion y Dieta de Cooper, 15. a ed. México, Interamericana, 1968.

ARAUJO, J. de - Diretrizes para a alimentação do lactante sadio. São Paulo, Nestle, 1962.

ALCANTARA, P. e MARCONDES, E. e MACHADO, D. - Mãe e filho: noções de puericultura. 3.a ed., São Paulo, Saraiva, 1968.

NELSON, W. E. et al - Tratado de Pediatria - Alimentaçion durante la primeira infancia. 5.a ed., Barcelona, Salvat, 1959.

EL VALOR incomparable de la leche humana - Boletin de la Oficina Sanitaria Panamericana. 71 (6): 519-529, dec. 1971.

RIBEIRO, A. et al - Alimentação da criança de 0 a 1 ano. Rev. da Esc. Enf. USP, 7 (1) :

Esc. Enf. USP, 7 (1): 104-113 